\title{
Prognosis of deeply comatose patients on ventilators
}

\author{
Tsu-pei Hung, Sien-Tsong Chen
}

\begin{abstract}
Although the concept of brain death has been widely accepted, the criteria required for making the diagnosis remain controversial. This prospective study was undertaken to examine the reliability of a set of clinical criteria adopted in Taiwan. One hundred and forty deeply comatose patients (101 men, 39 women; mean age 49.5 (SD 17.6) years) requiring ventilation were studied. Seventy three patients met the clinical criteria for brainstem death; all developed cardiac asystole ( $97 \%$ within seven days) despite continued full cardiorespiratory support. Brainstem death was diagnosed in only two of the 21 patients with hypoxic or ischaemic insults. This stresses the rarity of hypoxic or ischaemic encephalopathy as a cause of brainstem death. The results show that if strict attention is paid to preconditions and exclusions, brainstem death can be reliably diagnosed on clinical grounds alone.
\end{abstract}

(F Neurol Neurosurg Psychiatry 1995;58:75-80)

Keywords: brain death; clinical grounds; ventilation

The traditional concept of death was based on the loss of heart and lung functions. As the cessation of these functions was easily observable, there was little argument about how to determine death. During the past two decades, however, traditional views concerning death have been questioned and modified. This was partly due to the advent of modern resuscitative equipment, which enabled the cardiopulmonary functions to be maintained artificially. Death can therefore no longer be equated with the loss of spontaneous breathing or heart beat. Also, cumulative data have shown that in the presence of massive and irreversible damage to the brainstem artificial maintenance of cardiopulmonary functions could not really save life. Indeed, cardiac arrest eventually occurs in all patients diagnosed as brainstem dead. ${ }^{1}$ With limited medical and financial resources, continued ventilation of such a person may deprive other patients of needed care. Furthermore, in this era of organ transplantation the potential benefits of obtaining organs in good condition are lost if death is pronounced only after cardiovascular collapse has occurred. For these reasons, further thought about what is meant by death is needed.
Brain death has been widely accepted as evidence of death since the first formal criteria for its identification were published in 1968 by the ad hoc committee of the Harvard Medical School. ${ }^{2}$ There is still controversy, however, concerning the actual criteria for its determination..$^{3-9}$ Some authors consider that clinical examination only is enough to describe a state from which recovery of consciousness is never seen and asystole within a short period is inevitable. Others suggest that certain tests, such as EEG or arteriography, are necessary to establish the diagnosis. In Taiwan, a set of criteria for determination of brain death, based on clinical ascertainment of irreversible loss of brainstem function (a dead brainstem), was proposed by the ad hoc committee of the Neurological Society on brain death in 1985 and was adopted by the Department of Health in September 1987.

The purpose of this study was to examine the reliability of these criteria and to observe the ultimate outcome of patients diagnosed as brainstem dead. As cumulative data are needed to validate the accuracy of a clinical diagnosis of brain death, and the consequences of continued ventilation of patients who are brainstem dead have seldom been specifically studied, we now present our experience on this issue.

\section{Patients and methods}

The patients enrolled in this study were all deeply comatose (Glasgow coma scale 3-5 points) and all had required artificial ventilation for at least 12 hours. They were all under the care of neurologists in intensive care units, or were being seen and followed up by neurologists through consultation. All of the enrolled patients were therefore the subjects of detailed, serial neurological examination, and a clear outcome record was available in each instance. Excluded from this study were patients who recovered from apnoeic coma or who developed asystole during the minimum observation period of 12 hours.

A total of 140 patients were included in this study: 73 were patients at the National Taiwan University Hospital between May 1985 and December 1989, and 67 were patients at the Chang Gung Memorial Hospital between February 1986 and January 1990. There were 101 men and 39 women, whose ages ranged from 2 years and 3 months to 89 years, with a mean of 49.5 (SD 17.6) years. 


\section{Table 1 Criteria for determination of brain death (the Taiwan code)}

Preconditions:

(1) The patient is in deep coma, apnoeic, and on a ventilator.

(2) The cause of coma has been fully established.

(3) The patient has irremediable, structural brain damage.

Exclusions:

(1) Comas due to metabolic disturbance, drug intoxication, and hypothermia have been excluded. These factors are not contributing to the patient's coma.

(2) Comas of undetermined cause should always be excluded.

Observation period:

The period of observation for a comatose patient on a ventilator should be at least 12 hours. During this period the patient should remain deeply comatose with no spontaneous

breathing, abnormal postures or movement, or epileptic jerking.

(1) If the cause of coma is clearly due to primary structural brain damage, a period of 12 hours is enough for observation.

(2) If the coma is due to structural brain damage combined with the possibility of drug intoxication, it is necessary to wait for a period equal to the half life of the drug, and to observe for a further 12 hours. If the drug causing the coma is not known, an observation period of at least 72 hours is needed.

Diagnostic tests for brainstem function:

All the above three conditions must be rigorously fulfilled before proceeding to diagnostic tests for the confirmation of brain death.

(1) Testing for absence of all brain stem reflexes includes:

(a) No oculocephalic reflex.

(c) No corneal reflex.

d) No vestibulo-ocular reflex.

No motor response within the cranial nerve distribution in response to adequate

(f) No gag reflex or reflex response to bronchial stimulation by suction catheter passed down the trachea.

(2) Testing of apnoea:

(a) Preoxygenate with $100 \% \mathrm{O}_{2}$ for 10 minutes then administer $5 \% \mathrm{CO}_{2}$ in $95 \% \mathrm{O}_{2}$ for a further five minutes to ensure starting $\mathrm{PaCO}_{2}$ of $40 \mathrm{~mm} \mathrm{Hg}$.

(b) Disconnect from the ventilator. Insufflate trachea with $100 \%$ oxygen at $6 \mathrm{Vmin}$ through intratracheal catheter passed to carina.

(c) Maintain disconnection for 10 minutes to see if there is any spontaneous breathing

(d) If absolute apnoea has been ascertained, reconnect the ventilator to the patient.

Retests of brainstem function:

For a diagnosis of brain death the above brainstem function tests should be repeated at least four hours later with same results.
Brain damage due to cardiac or respiratory failure may be irreversible. Severity and potential for recovery are, however, sometimes difficult to determine. To obtain better data for this group of patients, we separated hypoxic or ischaemic brain insults from primary structural brain damage. Excluded from this group were patients whose apnoeic comas were obviously due to irreversible cardiopulmonary impairment or extensive multiple organ failure, because accurate assessment of irremediable structural brain damage contributing to coma could not be made in such patients (preconditions and exclusions not fulfilled). Thus the 21 patients with hypoxia or ischaemia enrolled in this study were those who sustained apnoeic coma after a successful cardiopulmonary resuscitation.

Nineteen comatose and ventilated patients who did not fulfil the preconditions and exclusions were classified in the group of nonstructural brain dysfunction. None of these patients had persistent focal neurological deficits during the observation period except for one patient with frontal meningioma receiving barbiturate coma treatment. Patients in this group often showed fluctuations in their depth of coma and brainstem responses. Therefore, whenever the score on the Glasgow coma scale fell to 3 points, the results of testing for brainstem reflexes were recorded as representative data for this study.

The relevance of the EEG to the diagnosis of brain death has been the subject of major controversy. In this study, EEG was performed in 15 patients after the diagnosis of brainstem death. The recordings were made with a Nihon Koden, Model 5109 machine (Tokyo, Japan) according to the recommendations of the American Electroencephalographic Society for EEG recording in suspected cerebral death. ${ }^{10}$ The important points included interelectrode distances of at least $10 \mathrm{~cm}$, electrode impedances under 10000 but over $100 \mathrm{ohm}$, time constants of 0.3 to 0.4 seconds, a recording time of at least 30 minutes, and a sensitivity of $2.5 \mu \mathrm{V} / \mathrm{mm}$ during part of the record.

To assess ultimate outcome every patient in this study was treated with all necessary means, and without reservations. Patients diagnosed as brainstem dead were mechanically ventilated until cardiac asystole supervened. None of the cases were organ donors.

Table 2 Classification, brainstem reflexes, and outcome in 140 deeply comatose and ventilated patients

\begin{tabular}{|c|c|c|c|c|}
\hline & Brainstem death & Cardiac death & Vegetative state & Recovery \\
\hline \multicolumn{5}{|l|}{$\begin{array}{l}\text { Preconditions/exclusions fulfilled }(\mathrm{n}=121) \text { : } \\
\text { Primary structural brain damage }(\mathrm{n}=100)\end{array}$} \\
\hline All brainstem reflexes absent & 71 & - & - & - \\
\hline Some brainstem reflexes preserved & - & 21 & 8 & - \\
\hline Hypoxia or ischaemia $(n=21)$ & & & & \\
\hline All brainstem reflexes absent & 2 & - & - & - \\
\hline Some brainstem reflexes preserved & - & 10 & 9 & - \\
\hline Preconditions/exclusions not fulfilled $(n=19)$ : & & & & \\
\hline All brainstem reflexes absent & - & 7 & - & - \\
\hline Some brainstem reflexes preserved & - & 8 & 3 & 1 \\
\hline Total $(n=140)$ & 73 & 46 & 20 & 1 \\
\hline
\end{tabular}


Table 3 Aetiological classification and outcome in 140 deeply comatose and ventilated patients

\begin{tabular}{|c|c|c|c|c|}
\hline Aetiology & Brainstem death & Cardiac death & Vegetative state & Recovery \\
\hline \multicolumn{5}{|l|}{ Primary structural brain damage $(n=100)$ : } \\
\hline Head injury $(n=40)$ & 35 & 1 & 4 & - \\
\hline Cerebral haemorrhage $(n=35)$ & 20 & 13 & 2 & - \\
\hline Cerebral infarction $(\mathrm{n}=12)$ & 3 & 7 & 2 & - \\
\hline Subarachnoid haemorrhage $(n=6)$ & 6 & - & - & - \\
\hline Brain tumour $(n=5)$ & 5 & - & - & - \\
\hline Brain abscess $(\mathrm{n}=1)$ & 1 & - & - & - \\
\hline Herpes encephalitis $(n=1)$ & 1 & - & - & - \\
\hline \multicolumn{5}{|l|}{ Hypoxia or ischaemia $(n=21)$ : } \\
\hline Cardiac diseases $(n=13)$ & 2 & 5 & 6 & - \\
\hline Pulmonary diseases $(n=5)$ & - & 5 & - & - \\
\hline Electric shock with cardiac arrest $(n=2)$ & - & - & 2 & - \\
\hline Mine accident with suffocation $(n=1)$ & - & 一 & 1 & - \\
\hline \multicolumn{5}{|l|}{ Non-structural brain dysfunction $(n=19)$ : } \\
\hline Drug intoxication $(n=6)$ & - & 4 & 1 & 1 \\
\hline Hypovolaemic/septic shock $(n=6)$ & - & 5 & 1 & - \\
\hline Uraemia $(n=4)$ & - & 4 & - & - \\
\hline Hypoglycaemia $(n=1)$ & - & - & 1 & - \\
\hline Barbiturate coma treatment $(\mathrm{n}=1)^{\star}$ & - & 1 & - & - \\
\hline Unknown $(n=1)$ & - & 1 & - & - \\
\hline Total $(n=140)$ & 73 & 46 & 20 & 1 \\
\hline
\end{tabular}

^For treatment of severe intracranial hypertension and status epilepticus in a patient with meningioma.

\section{Results}

CLASSIFICATION, BRAINSTEM REFLEXES, AND OUTCOME

Table 2 shows the results of testing for brainstem reflexes and the clinical outcome in each group of patients. Among the 100 patients with primary structural brain damage, 71 had lost all brainstem reflexes and were diagnosed as brainstem dead after confirmation of apnoea. Twenty nine patients in this group retained some brainstem reflexes: 21 died of cardiac arrest, and eight became vegetative. In the hypoxia or ischaemia group, only two patients had lost all brainstem functions and were diagnosed as brainstem dead; in the remaining 19 patients who retained some brainstem reflexes, 10 died of cardiac arrest and nine turned out to be in a vegetative state. Among the 19 patients with non-structural brain dysfunction, seven lost all brainstem reflexes, absolute apnoea was not ascertained, and these seven patients all died of cardiac arrest; 12 patients retained some brainstem reflexes - eight died of cardiac arrest, three became vegetative, and one recovered well.

CAUSES OF APNOEIC COMA AND OUTCOME

Table 3 tabulates the causes of apnoeic coma in these 140 patients. Brainstem death was diagnosed mainly in the primary structural brain damage group; head injury was the most common cause (35), then cerebral haemorrhage (20), subarachnoid haemorrhage (six), brain tumour (five), and cerebral infarction (three). Of the 21 patients with hypoxic or ischaemic encephalopathy, 13 were due to cardiac diseases, including acute myocardial infarction, congestive heart failure, pericardial effusion, and aortic dissection; five were due to pulmonary diseases, including pulmonary oedema, pulmonary embolism, and adult respiratory distress syndrome; two had had electric shock with cardiac arrest, and one was a victim of a mine accident (suffocation). Among these 21 patients, only two had lost all brainstem functions and were diagnosed as brainstem dead. Nineteen patients had nonstructural brain dysfunction (preconditions and exclusions not fulfilled); these included drug intoxication in six (parathion, paraquet, chlorofom, xylocaine, or alcohol intoxication), hypovolaemic or septic shock in six, uraemia in four, hypoglycaemia in one, and coma of unknown cause in one (a patient with hepatoma who developed apnoeic coma during injection of alcohol into the cancer site for palliative treatment). A patient with a large frontal meningioma was also considered as not fulfilling the necessary exclusions because he was receiving barbiturate coma treatment for severe intracranial hypertension and status epilepticus. The only patient who survived and recovered well was the one with alcohol intoxication.

\section{APNOEA TEST}

At the beginning of this study in $1985,5 \%$ $\mathrm{CO}_{2}$ was not available in wards and intensive care units in most hospitals. To ensure a $\mathrm{PaCO}_{2}$ level of at least $40 \mathrm{~mm} \mathrm{Hg}$ before disconnection, the ventilator was slowed down to overcome hyperventilation and hypocapnoea which were often seen in patients on a ventilator. Since September 1987, breathing 5\% $\mathrm{CO}_{2}$ in $95 \% \mathrm{O}_{2}$ for five minutes before disconnection has become a mandatory procedure for the apnoea test (table 1). Table 4 lists the mean values and ranges of $\mathrm{PaO}_{2}$ and $\mathrm{PaCO}_{2}$ in 41 brainstem dead patients before administration of $5 \% \mathrm{CO}_{2}$ in oxygen and before

Table 4 Blood gas data from apnoea test in 41 brainstem dead patients

\begin{tabular}{|c|c|c|c|c|}
\hline & \multicolumn{2}{|l|}{$\mathrm{PaO}_{2}(\mathrm{~mm} \mathrm{Hg})$} & \multicolumn{2}{|c|}{$\mathrm{PaCO}_{2}(\mathrm{~mm} \mathrm{Hg})$} \\
\hline & Mean (SD) & Ranges & Mean $(S D)$ & Ranges \\
\hline $\begin{array}{l}\text { Before breathing } 5 \% \mathrm{CO}_{2} \text { in oxygen } \\
\text { Before disconnection from ventilator } \\
10 \text { minutes off ventilator }\end{array}$ & $\begin{array}{l}158 \cdot 7(90 \cdot 4) \\
488 \cdot 2(95 \cdot 9) \\
324 \cdot 6(114 \cdot 9)\end{array}$ & $\begin{array}{r}71 \cdot 1-475 \cdot 9 \\
207 \cdot 9-610 \cdot 0 \\
101 \cdot 7-534 \cdot 5\end{array}$ & $\begin{array}{l}30 \cdot 9(5 \cdot 1) \\
48 \cdot 0(7 \cdot 4) \\
79 \cdot 8(12 \cdot 4)\end{array}$ & $\begin{array}{l}20 \cdot 0-47 \cdot 3 \\
38 \cdot 5-67 \cdot 3 \\
56 \cdot 3-102 \cdot 9\end{array}$ \\
\hline
\end{tabular}


Table 5 EEG findings and clinical outcome in 15 brainstem dead patients

\begin{tabular}{lcll}
\hline EEG findings & $\begin{array}{l}\text { No of patients } \\
(\%)\end{array}$ & $\begin{array}{l}\text { Asystole after } \\
\text { brainstem death }\end{array}$ & $\begin{array}{l}\text { Duration from brainstem } \\
\text { death to asystole }(h)\end{array}$ \\
\hline Isoelectric $(<2.5 \mu \mathrm{V})$ & $5(33)$ & all & $9,12,15,25,27$ \\
Low potential $(<5 \mu \mathrm{V})$ & $3(20)$ & all & $8,20,77$ \\
Residual activity & $7(47)$ & all & $8,11,20,23,25,48,72$ \\
Total & $15(100)$ & & \\
\hline
\end{tabular}

disconnection from the ventilator (after breathing $5 \% \mathrm{CO}_{2}$ for five minutes), and during 10 minutes off the respirator. The $\mathrm{PaCO}_{2}$ level before disconnection was usually more than $40 \mathrm{~mm} \mathrm{Hg}$ (mean $48 \cdot 0$ (SD $7 \cdot 4$ ), range $38 \cdot 5-67 \cdot 3 \mathrm{~mm} \mathrm{Hg}$ ), and rose to at least 60 $\mathrm{mm} \mathrm{Hg}$ in most cases during 10 minutes of disconnection (mean 79.8 (SD 12.4), range 56.3-102.9 mm Hg). The mean $\mathrm{PaO}_{2}$ level during 10 minutes off the ventilator was $324 \cdot 6$ (SD 114.9$) \mathrm{mm} \mathrm{Hg}$, with a range of 101.7 to $534.5 \mathrm{~mm} \mathrm{Hg}$.

\section{EEG FINDINGS AND OUTCOME}

All the EEGs were performed within 24 hours of the clinical diagnosis of brainstem death. Of the 15 patients studied, seven ( $47 \%$ ) were found to have obvious residual activity, three $(20 \%)$ had very low potential $(<5 \mu \mathrm{V})$ tracing, and only five $(33 \%)$ fulfilled the criteria of electrocerebral silence (table 5). Regardless of the EEG findings, all 15 patients developed cardiac asystole within 77 hours of the clinical diagnosis of brainstem death.

\section{OUTCOME OF BRAINSTEM DEAD PATIENTS}

Despite every necessary treatment, including artificial ventilation, cardiac asystole occurred in all 73 patients whose clinical diagnosis of brainstem death had been made (table 6): within three days in 59 patients $(81 \%)$, and within seven days in $71(97 \%)$.

\section{Discussion}

The concept of brain death has evolved during the 30 years since two French physicians described in 1959 a clinical condition they called "coma dépassé"." At that time organ transplantation was in its infancy. It is now well acknowledged that the brain is the

Table 6 Elapse of time from brainstem death to asystole in 73 cases

\begin{tabular}{lcc}
\hline Duration & & \\
\cline { 1 - 2 } Hours & Days & No of cases \\
\hline$<3-6$ & & 2 \\
3 & & 3 \\
$6-12$ & & 9 \\
$12-24$ & & 19 \\
$24-48$ & $1-2$ & 16 \\
$48-72$ & $2-3$ & 10 \\
$72-96$ & $3-4$ & 5 \\
$96-120$ & $4-5$ & 3 \\
$120-144$ & $5-6$ & 1 \\
$144-168$ & $6-7$ & 3 \\
229 & $9 \cdot 5$ & 1 \\
397 & $16 \cdot 5$ & 1 \\
Total & & 73 \\
\hline
\end{tabular}

essence of life; when brain death is accurately diagnosed consciousness will never return to the patient even with continuous cardiopulmonary support. There exists a critical issue, however, which is what actually constitutes adequate proof of brain death.

A theoretical definition of brain death might be the "irreversible loss of all brain functions". But clinically, a set of operational criteria is needed to make the diagnosis feasible. In general, there are two ways of achieving this end. ${ }^{12}{ }^{13}$ Firstly, we might seek to use some instrument that would reliably detect brain pathology, allowing total and irreversible destruction of the brain to be determined. Unfortunately, no such laboratory device is available at the present time. Secondly, we might seek to establish a set of clinical criteria that can predict the total loss of brain functions and which, when fulfilled, imply that asystole is inevitable within a short period. The reliability of such clinical criteria depends on the accumulation of data predicting asystole. As the development of medicine, sociocultural backgrounds, and the legal considerations differ in many countries, it is not surprising that the criteria for the determination of brain death may also differ.

One of the most important developments of the brain death concept was made in 1971 by two neurosurgeons ${ }^{14}$ in the United States who reported that "in patients with known but irreparable intracranial lesions", irreversible damage to the brainstem was the "point of no return". The diagnosis of brainstem death could be "established solely on clinical grounds". This concept was clearly reflected in the memorandum ${ }^{15}$ for the diagnosis of brain death endorsed by the Conference of Medical Royal Colleges and their Faculties of the United Kingdom (which has become known as the United Kingdom code), and was thoroughly discussed by Pallis in a monograph.

It is now well known that the assessment of brainstem function is pivotal to the diagnosis of brain death. The irreversible cessation of brainstem function implies the death of the "brain as a whole". Because the brainstem nuclei are closely and cephalocaudally located with respiratory centres in the lowermost segment, ${ }^{16}$ testing the various cranial nerve reflexes and respiration provides a systematic evaluation of brainstem function. When all brainstem reflexes have been lost and absolute apnoea has been confirmed, the cessation of all brainstem function is evident, and a hopeless cardiac prognosis can be predicted. In our present study, none of the 73 patients with irreversible brainstem areflexia and documented apnoea survived. Cessation of brain function may be temporary, however, when due to metabolic derangements, drug intoxications, or hypothermia. ${ }^{17-19}$ In these circumstances, brain functions may be suppressed but brain structure may not be appreciably damaged. After proper treatment, recovery is possible. A patient in our series went into deep apnoeic coma from severe alcoholic intoxication, but recovered. Exclusion of 
reversible causes of loss of brainstem function is thus crucial to the diagnosis of brain death. For patients with coma of unknown cause, such exclusion procedures may be laborious, and may require a wide variety of toxic and metabolic screenings. Our criteria exclude coma of unknown cause. This precondition minimises the fear of mistaking toxic or metabolic coma for brainstem death.

To ensure the irreversibility of the loss of brainstem functions, a suitable time of observation is mandatory. In our criteria, an observation period of at least 12 hours is necessary for patients with primary structural brain damage. If there is any suspicion of concomitant intoxication, the observation time should be prolonged according to the half life of the drug suspected. If concomitant intoxication with some unknown drug is suspected the observation period should be over 72 hours.

In our study, patients with primary structural brain damage were the main group in which brainstem death was diagnosed. Of the various causes within this group, head injury was the most common, followed by intracranial (cerebral and subarachnoid) haemorrhages, and brain tumour. Other rare intracranial conditions included brain abscess and encephalitis. Although severe brain damage may be sustained by patients with cardiopulmonary arrest (if resuscitation fails within five minutes), such insult usually predominantly damages the cerebral cortex and cerebellum. ${ }^{20}{ }^{21}$ Brainstem death due to cardiac and respiratory arrest and hypoperfusion of the brain is relatively rare. ${ }^{7}$ In our series, most patients with cerebral hypoxia or ischaemia developed asystole or ended up in a vegetative state. Only two of the 21 patients in this category met the criteria for brainstem death. Because transient suppression of brain functions often occurs after resuscitation and because many drugs used during resuscitation may hinder reliable neurological assessment, the diagnosis of brainstem death in cerebral hypoxia or ischaemia should only be made with extreme caution.

The test for apnoea is the most critical of all tests of brainstem function. In our study, only patients who had fulfilled the preconditions and exclusions and had shown no brainstem reflexes received the apnoea test. The use of $5 \% \mathrm{CO}_{2}$ in $95 \% \mathrm{O}_{2}$ before disconnection successfully raised the $\mathrm{PaCO}_{2}$ to an appropriate "starting" level - that is, around $40 \mathrm{~mm} \mathrm{Hg}$. During 10 minutes off the respirator, the $\mathrm{PaCO}_{2}$ rose to at least $56 \mathrm{~mm} \mathrm{Hg}$, which is an adequate level to stimulate the respiratory centre. The patient who could not breathe at these high levels of $\mathrm{PaCO}_{2}$ is thus deemed incapable of breathing. Preoxygenation before and diffusion oxygenation during disconnection ensured $\mathrm{a} \mathrm{PaO}_{2}$ of at least $101.7 \mathrm{~mm} \mathrm{Hg}$ ( $>200 \mathrm{~mm} \mathrm{Hg}$ in most cases). From our study, it is evident that a well conducted apnoea test will never cause hypoxia in the tested patients.

Although the effectiveness of an isoelectric EEG in predicting asystole was documented in the early $1970 \mathrm{~s},{ }^{22-24}$ cases of recovery from electrocerebral silence have also been noted. ${ }^{25-28}$ Most of these were cases of drug intoxication, hypothermia, or metabolic disturbance. Based on the findings of the collaborative study ${ }^{4}$ conducted by the National Institute of Neurological and Communicative Disorders and Strokes, USA, up to $40 \%$ of persons meeting different sets of criteria for brain death had some activity in their EEGs. The question whether an isoelectric EEG should be a mandatory requirement for the determination of brain death was also raised by Powner and Fromm, ${ }^{29}$ who found that $14 \%$ of their patients with a clinical diagnosis of brain death did not have isoelectric EEGs. All patients developed asystole, however. Our data are similar to these. Only $33 \%$ of our clinically brainstem dead patients with an EEG study showed an isoelectric tracing; nevertheless, cardiac asystole occurred in all patients within days. The low yield of isoelectric EEGs in our brainstem dead patients is understandable as EEG is essentially a test for cortical function, which is not a crucial part for determination of irreversible loss of brainstem function-a dead brainstem that is the physiological core of brain death implying the death of the brain as a whole. ${ }^{8}$

Despite full cardiopulmonary support, all patients diagnosed as brainstem dead in this study sustained cardiac asystole. This occurred within seven days in $97 \%$ of the patients. The result is consistent with previous reports. ${ }^{13031}$ The mechanism for the irreversible cessation of heart beat in brainstem dead patients is unknown. It has long been understood that the heart is constantly under cholinergic and adrenergic nervous control and may be affected by some diseases of the nervous system. ${ }^{32} 33$ Several neuropeptides such as tyrosine, histamine, and cimetidine are closely related to cardiac function. ${ }^{34-36}$ Recently, a combined treatment of vasopressin and catecholamines was reported to stabilise and maintain circulation for a prolonged time in brain dead patients. ${ }^{37} 38$ Low concentrations of free triiodothyronine in the serum of brain dead patients, ${ }^{39}$ and an association of a low concentration of free triiodothyronine with a deterioration in cardiac function, ${ }^{40}$ have also been found. Anterior and posterior pituitary hormones have been implicated in the maintenance of circulatory function in brain dead patients, ${ }^{37-40}$ but this needs further elucidation. Nevertheless, it is considered that the heart will stop beating once the effective control of the nervous system has been completely lost. It should also be mentioned that neuropathological studies in brain dead patients show postmortem autolysis, ${ }^{3}$ which is the same pathological process occurring in cardiac death.

In conclusion, our data confirm the belief that brainstem death can be reliably diagnosed on clinical findings alone. When full attention is given to the preconditions and necessary exclusions, and when the doctors carrying out the tests are adequately competent, the diagnosis of brainstem death based on clinical assessment is scientifically justified. 
1 Pallis C. Prognostic value of brainstem lesion. Lancet $1981 ; \mathbf{i}: 379$.

2 Ad Hoc Committee of the Harvard Medical School to Examine the Definition of Brain Death. A definition of irreversible coma. $\Im A M A$ 1968;205:337-40.

3 Walker AE. Cerebral death. 3rd ed. Baltimore-Munich Urban and Schwarzenberg, 1985:157-95.

4 American Collaborative Study. An appraisal of the criteria of cerebral death. A summary statement. $\mathfrak{F} A M A 1977$ 237:982-6.

5 Black PM. Brain death (first of two parts). $N$ Engl f Med 1978;299:338-44.

6 Black PM. Brain death (second of two parts). $N$ Engl $\mathcal{F}$ Med 1978;299:393-401.

7 Pallis C. $A B C$ of brain stem death. London: British Medical Association, 1983.

8 Pallis C. Brainstem death. In: Vinken PJ, Bruyn GW, Klawans HL, Braakman R, eds. Handbook of clinical Klawans HL, Braakman R, eds. Handbook of clinical
neurology. Vol 57: Head injury. Amsterdam: Elsevier neurology. Vol 57: Head injury.

9 President's Commission for the Study of Ethical Problems in Medicine and Behavioral Research. Defining death. Medical legal and ethical issues in the determination of death. Washington, DC: US Government Printing Office, 1981.

10 American Electroencephalographic Society. Minimum technical standards for EEG recording in suspected cerebral death. In: Klass DW, Daly DD, eds. Curren practice of clinical electroencephalography. New York: Raven Press, 1979:492-6.

11 Mollaret $P$, Goulon M. Le coma dépassé (Mémoire préliminaire). Rev Neurol 1959;101:3-15.

12 Black PM. From heart to brain: the new definitions of death. Am Hear ₹ 1980;99:279-81.

13 Black PM. Clinical problems in the use of brain-death standards. Arch Intern Med 1983;143:121-3.

14 Mohandas A, Chou SN. Brain death-a clinical and pathological study. 7 Neurosurg 1971;35:211-8.

15 Conference of Medical Royal Colleges and their Faculties of the United Kingdom. Diagnosis of brain death. $B M Y$ 976;2:1187-8

16 Berger AJ, Mitchell RA, Severinghaus JW. Regulation of respiration (Part 2). N Engl f Med 1977;297:138-43.

17 Plum F, Posner JB. Diagnosis of stupor and coma, 3rd ed. Philadelphia: Davis, 1980

18 Bird TD, Plum F. Recovery from barbiturate overdose coma with a prolonged isoelectric electroencephalogram. Neurology 1968;18:456-60.

19 Silverman D, Saunders MG, Schwab RS, et al. Cerebra death and the electroencephalogram. $\mathcal{F} A M A$ 1969;209: $1505-10$.

20 Levy DE, Brierley JB, Silverman DG, et al. Brief hypoxiaischaemia initially damages cerebral neurons. Arch Neurol 1975;32:450-6.

21 Weinberger LM, Gibbon $\mathrm{MH}$, Gibbon $\mathrm{JH}$. Temporary arrest of circulation to the central nervous system: II.
Pathologic effects. Arch Neurol Psychiatry 1940;43: 961-86.

22 Silverman D, Masland RL, Saunders MG, Schwab RS Irreversible coma associated with electrocerebral silence. Neurology 1970;20:525-33.

23 Korein J, Maccario M. On the diagnosis of cerebral death A prospective study on 55 patients to define irreversible coma. Clin Electroencephalogr 1971;2:178-99.

24 Jørgensen EO. EEG without detectable clinical activity and cranial nerve areflexia as parameters of brain death. Electroencephalogr Clin Neurophysiol 1974;36:70-5.

25 Levin P, Kinnell J. Successful cardiac resuscitation despite prolonged silence of EEG. Arch Intern Med 1966;117: p57-60.

26 Tyson RN. Simulation of cerebral death by succinylcholine sensitivity. Arch Neurol 1974;30:409-11.

27 Powner DJ. Drug-associated isoelectric EEG. A hazard in brain-death certification. $¥ A M A 1976 ; 236: 1123$.

28 Green JB, Lauber A. Return of EEG activity after electrocerebral silence. Two case reports. $\mathcal{F}$ Neurol Neurosurg Psychiatry 1972;35:103-7.

29 Powner DJ, Fromm GH. The electroencephalogram in the determination of brain death [letter]. $N$ Engl $\mathcal{F} \mathrm{Med}$ 1979;300:502.

30 Jennet $B$, Gleave J, Wilson P. Brain death in three neurosurgical units. $B M F 1981 ; 282: 533-9$.

31 Shiogai T, Takeuchi K. Brain death in a neurosurgical unit in Japan. No To Shinkei (Brain and Nerve) 1984;36: 781-7. (In Japanese with English abstract.)

32 Natelson BH. Neurocardiology. An interdisciplinary area for the 80's. Arch Neurol 1985;42:178-84.

33 Talman WT. Cardiovascular regulation and lesions of the central nervous system. Ann Neurol 1985;15:1-12.

34 Gu J, Polak JM, Adrian TE, et al. Neuropeptide tyrosine (NPY) - a major cardiac neuropeptide. Lancet 1983;i: $1008-10$.

35 Bristow MR, Ginsburg R, Harrison DC. Histamine and the human heart: The other receptor system. Am $\mathcal{f}$ Cardiol 1982;49:249-51.

36 Reding P, Devroede C, Barbier P. Bradycardia after cimetidine. Lancet 1977;ii: 1227.

37 Yoshioka T, Sugimoto $\mathrm{H}$, Uenishi $\mathrm{M}$, et al. Prolonged hemodynamic maintenance by the combined administration of vasopressin and epinephrine in brain death: a clinical study. Neurosurgery 1986;18:565-7.

38 Iwai A, Sakano T, Uenishi M, et al. Effects of vasopressin and catecholamines on the maintenance of circulatory stability in brain-dead patients. Transplantation 1989;48: 613-7.

39 Novitzky D, Cooper DKC, Reichart B. Hemodynamic and metabolic responses to hormonal therapy in brain-dead potential organ donors. Transplantation 1987;43:852-4.

40 Novitzky D, Cooper DKC, Morrell D, et al. Change from aerobic to anaerobic metabolism after brain death, and reversal following triiodothyronine therapy. Transplantation 1988;45:32-6. 